\title{
Health Physics Enrollments and Degrees Survey, 2009 Data
}

\section{SURVEY UNIVERSE}

The survey includes degrees granted between September 1, 2008 and August 31, 2009. Enrollment information refers to the fall term 2009. Twenty-four academic programs were included in the survey universe, and all 24 programs provided data. Two programs within engineering departments that have provided data for health physics options programs in past years reported all data in the nuclear engineering survey starting in 2009. The enrollment and degree data includes students majoring in health physics or in an option program equivalent to a major.

\section{DEGREE DATA}

Bachelor's Degrees. The number of B.S. degrees granted in 2009 was slightly higher than in 2008 (based on the comparable data shown in parentheses) and continued the higher numbers reported since 2004. (See Table 1.) The current number of B.S. degrees is still approximately $25 \%$ below the number of B.S. degrees reported in the mid-1990s. Health physics programs accounted for over $90 \%$ of all B.S. degrees. (See Table 2.)

Graduate Degrees. The number of master's degrees granted in 2009 (based on the comparable data) was $21 \%$ less than in 2008 and similar to the numbers reported prior to 2008 . The number of doctorate degrees granted in 2009 and 2008 are the lowest reported since the survey began over 40 years ago. (See Table 1.) Health physics programs accounted for $59 \%$ of the master's degrees and $44 \%$ of the doctorate degrees. (See Table 2.)

Table 1. Health Physics Degrees, $2003-2009^{1}$

\begin{tabular}{cccc} 
& \multicolumn{3}{c}{ Degrees } \\
\cline { 2 - 4 } Year & B.S. & M.S. & Ph.D. \\
\hline 2009 & 69 & 76 & 9 \\
2008 & $73(64)$ & $108(96)$ & $8(8)$ \\
2007 & $79(66)$ & $91(79)$ & $28(18)$ \\
2006 & $71(55)$ & $90(76)$ & $12(9)$ \\
2005 & $78(57)$ & $77(65)$ & $14(11)$ \\
2004 & $54(44)$ & $64(56)$ & $14(9)$ \\
2003 & $56(47)$ & $73(64)$ & $25(20)$
\end{tabular}

${ }^{1}$ The degree data in parentheses has been adjusted to be comparable to the 2009 data that does not include data from two programs that were reported in earlier years.

Table 2. Health Physics Degrees by Curriculum, 2009

\begin{tabular}{lrrc}
\multicolumn{1}{c}{ Curriculum } & B.S. & M.S. & Ph.D. \\
\hline Health Physics Program & 63 & 45 & 4 \\
Medical Health Physics & 1 & 29 & 4 \\
Other Health Physics Option & 5 & 2 & 1
\end{tabular}




\section{ENROLLMENTS AND SHORT-TERM OUTLOOK FOR DEGREE TRENDS}

Undergraduate Students. In 2009, the reported enrollment of junior and senior undergraduate students was approximately 230, a 5\% increase over 2008 (enrollment data was available for one of the two programs no longer providing health physics data). The small increase in 2009 in undergraduate enrollments made up for a small decrease in enrollments in 2008. Together, the enrollment data for these two years indicate that the number of B.S. degrees is likely to remain in the 70 to 75 range in 2010 and to increase modestly in 2011.

Graduate Students. Graduate enrollment in 2009 was approximately 370 students. Even on a comparative number basis, this is almost $10 \%$ lower than in 2008. The enrollment trends indicate that the number of M.S. degrees is likely to remain constant for the next two to three years. The number of doctorates degrees is likely to increase modestly over the next few years, as graduate enrollments have been higher for the past six years, and most of these students are still in the pipeline.

\section{CITIZENSHIP, GENDER, AND RACE/ETHNICITY OF DEGREE RECIPIENTS (TABLE 3)}

Gender. For those with data reported, females comprised $35 \%$ of the B.S. degree recipients, $28 \%$ of the M.S. degree recipients, and $44 \%$ of the Ph.D. recipients.

Citizenship. For those with data reported, all of B.S. degree recipients were U.S. citizens. Among M.S. degree recipients, $16 \%$ were non-U.S. citizens; and for doctorate degree recipients, $44 \%$ were non-U.S. citizens.

Race/Ethnicity. For those with data reported, among both the B.S. degree recipients and M.S. degree recipients, $14 \%$ of U.S. citizens were minorities. No minorities were reported for Ph.D. degree recipients.

Table 3. Gender, Citizenship, and Race/Ethnicity of Degree Recipients, 2009

Non-U.S. Citizens

\begin{tabular}{cccccc}
\multicolumn{2}{c}{ B.S. } & \multicolumn{2}{c}{ M.S. } & \multicolumn{2}{c}{ Ph.D. } \\
\hline Female & Male & Female & Male & Female & Male \\
\hline 0 & 0 & 4 & 8 & 1 & 3
\end{tabular}

U.S. Citizens

African/Black Americans

American Indians/Native Americans

Asian/Pacific Island Americans

Hispanic Americans

White/Caucasian Americans

Other or Unknown

(not reported = $26 \mathrm{BS} ; 1 \mathrm{MS} ;$ \& $0 \mathrm{PhD}$ )

Totals

3
0
0
0
12
0

$\begin{array}{llllll}15 & 28 & 21 & 54 & 4 & 5\end{array}$


Table 4. Health Physics Degrees, 2009, by Academic Institution

(alphabetical by state and then university)

Degrees

Sept. 1, 2008 - Aug. 31, 2009

\begin{tabular}{|c|c|c|c|c|}
\hline \multirow{2}{*}{ State } & \multirow{2}{*}{ Name of Institution } & & & \\
\hline & & B.S. & M.S. & Ph.D. \\
\hline CA & San Diego State University & 0 & 3 & 0 \\
\hline $\mathrm{CO}$ & Colorado State University & 0 & 5 & 0 \\
\hline DC & Georgetown University & 0 & 2 & 0 \\
\hline $\mathrm{FL}$ & University of Florida & 1 & 0 & 2 \\
\hline ID & Idaho State University & 4 & 3 & 0 \\
\hline IL & Illinois Institute of Technology & 0 & 3 & 0 \\
\hline IN & Purdue University & 26 & 1 & 0 \\
\hline LA & Louisiana State University & 0 & 5 & 0 \\
\hline MA & University of Massachusetts, Lowell & 2 & 13 & 1 \\
\hline $\mathrm{ME}$ & University of Maine & 4 & 0 & 0 \\
\hline $\mathrm{MO}$ & University of Missouri - Columbia & 0 & 7 & 1 \\
\hline $\mathrm{NJ}$ & Thomas Edison State College & 5 & 0 & 0 \\
\hline NM & University of New Mexico & 0 & 6 & 0 \\
\hline NV & University of Nevada, Las Vegas & 0 & 5 & 0 \\
\hline NY & Rensselaer Polytechnic Institute & 2 & 0 & 1 \\
\hline $\mathrm{OH}$ & University of Cincinnati & 0 & 7 & 2 \\
\hline OR & Oregon State University & 7 & 10 & 1 \\
\hline PA & Bloomsburg University of Pennsylvania & 5 & 0 & 0 \\
\hline SC & Clemson University & 0 & 0 & 1 \\
\hline SC & Francis Marion University & 4 & 0 & 0 \\
\hline $\mathrm{TN}$ & University of Tennessee & 9 & 2 & 0 \\
\hline $\mathrm{TN}$ & Vanderbilt University & 0 & 1 & 0 \\
\hline TX & University of Texas & 0 & 0 & 0 \\
\hline \multirow[t]{2}{*}{ WA } & Washington State University, Tri-Cities & 0 & 3 & 0 \\
\hline & TOTALS: & 69 & 76 & 9 \\
\hline
\end{tabular}


Prepared by: Analysis and Evaluation Group, Science Education Programs, Oak Ridge Institute for Science and Education, March 2010.

This document was prepared for U.S. Nuclear Regulatory Commission by the Oak Ridge Institute for Science and Education (ORISE) through an interagency agreement with the U.S. Department of Energy (DOE). ORISE is managed by Oak Ridge Associated Universities under DOE contract number DE-AC05-06OR23100.

The Oak Ridge Institute for Science and Education (ORISE) is a U.S. Department of Energy institute focusing on scientific initiatives to research health risks from occupational hazards, assess environmental cleanup, respond to radiation medical emergencies, support national security and emergency preparedness, and educate the next generation of scientists. ORISE is managed by Oak Ridge Associated Universities.

All opinions expressed in this report are the author's and do not necessarily reflect the policies and views of the U.S. Nuclear Regulatory Commission, the U.S. Department of Energy, or the Oak Ridge Institute for Science and Education or any of their employees. Nor does it necessarily reflect the policies and views of the sponsoring institutions of Oak Ridge Associated Universities. 